\title{
Vertebro-basilar ischaemia with thrombosis of the vertebral artery: report of two cases with embolism
}

\author{
B GEORGE,* C LAURIAN $\dagger$
} From the department of Neurosurgery, Hopital Lariboisière,* and the department of Vascular Surgery,
Hopital Saint-Joseph, $\dagger$ Paris, France

SUMMARY Two cases with vertebro-basilar infarcts associated with severe stenosis of the vertebral artery in its cervical part are reported. Complete thrombosis of the vertebral artery was observed after a short delay in both cases. As the carotid arteries were normal and the controlateral vertebral artery was dominant, an embolic mechanism was suspected. No new event occurred in the following one and three years respectively after the stroke. These two cases demonstrate the possibility of embolism from severe stenosis of the cervical vertebral artery. This mechanism could explain some of the infarcts related to vertebral artery occlusion.

The mechanisms causing vertebro-basilar ischaemia with thrombosis of the vertebral artery are not well understood. Sometimes the ischaemia appears likely to be related to low flow in the vertebro-basilar system; in other cases, an embolic mechanism is suggested, but proof is rarely afforded. We report two cases in which we believe that embolism from a severe stenosis occurred, and in which the stenosis subsequently evolved to complete thrombosis after a short delay.

\section{Case reports}

Mr P, aged 55 years, was referred having suffered from sudden onset of asthenia and hypersomnia and, 8 hours later, dysarthria, diplopia, and facial palsy. On admission hypersomnia was still present, associated with a Parinaud's syndrome, palsy of the left III, IV, and VII cranial nerves and rotatory nystagmus. CT scan showed a small lucent zone on the left side of the pontopeduncular junction. Bilateral brachial arteriography showed a normal right vertebral artery and a severe stenosis on the left vertebral artery between $\mathrm{C} 1$ and $\mathrm{C} 2$; the right was the dominant vertebral artery. The patient left the service for one month; on return, most of the symptoms had regressed; only the IV cranial nerve palsy and the rotatory nystagmus remained. On arteriography, the left carotid artery was normal and the left vertebral artery was

Address for reprint requests: Dr B George, Neurochirurgie Hopital Lariboisière, 2 Rue A Paré, 75010 Paris, France.

Received 4 March 1981 and in revised form 10 August 1981 Accepted 15 August 1981 completely thrombosed without any filling of the vessel (fig 1a). One year later, no new event had occurred and the patient was free of all symptoms apart from the rotatory nystagmus.

$\mathrm{Mr} \mathrm{D}$, aged 45 years, was referred for a sudden attack of headache, vomiting, and gait ataxia. The day before, he experienced a short episode of bilateral loss of vision and 6 months before, had had two episodes of vertigo. Neurological examination showed gait ataxia, left dysmetria and hypermetria, and right ptosis. Lumbar puncture was normal; isotopic scanning was normal; bilateral brachial arteriography showed a small ostial stenosis on the right vertebral artery and a severe ostial stenosis on the left vertebral artery (fig 1b). The right vertebral artery was the dominant vessel. Both carotid arteries were normal. Five months later, the cerebellar syndrome had decreased but not disappeared. A second arteriography demonstrated a complete thrombosis of the left vertebral artery. Three years later, the patient has improved but still has a gait ataxia and mild left hypermetria.

These two cases are taken from a series of 66 patients with vertebro-basilar ischaemia seen in a 3 year period. Thirty-two cases were with infarcts of the posterior inferior cerebellar arterial territory (cerebellar or lateral medullary infarcts) (PICA I) and 34 cases with involvement of the basilar trunk territory (brain stem or occipital infarcts). (BT I). Complete arteriographic investigations were performed in 44 cases. Significant lesions of the cervical vertebral artery (stenosis of more than $50 \%$ ) or occlusion were found in $65 \%$ of BT I and in $80 \%$ of PICA I (15 significant stenosis and 17 occlusion). Topography of the lesions was mainly ostial for occlusion and ostial and in the third portion for stenosis. Bilateral lesions 


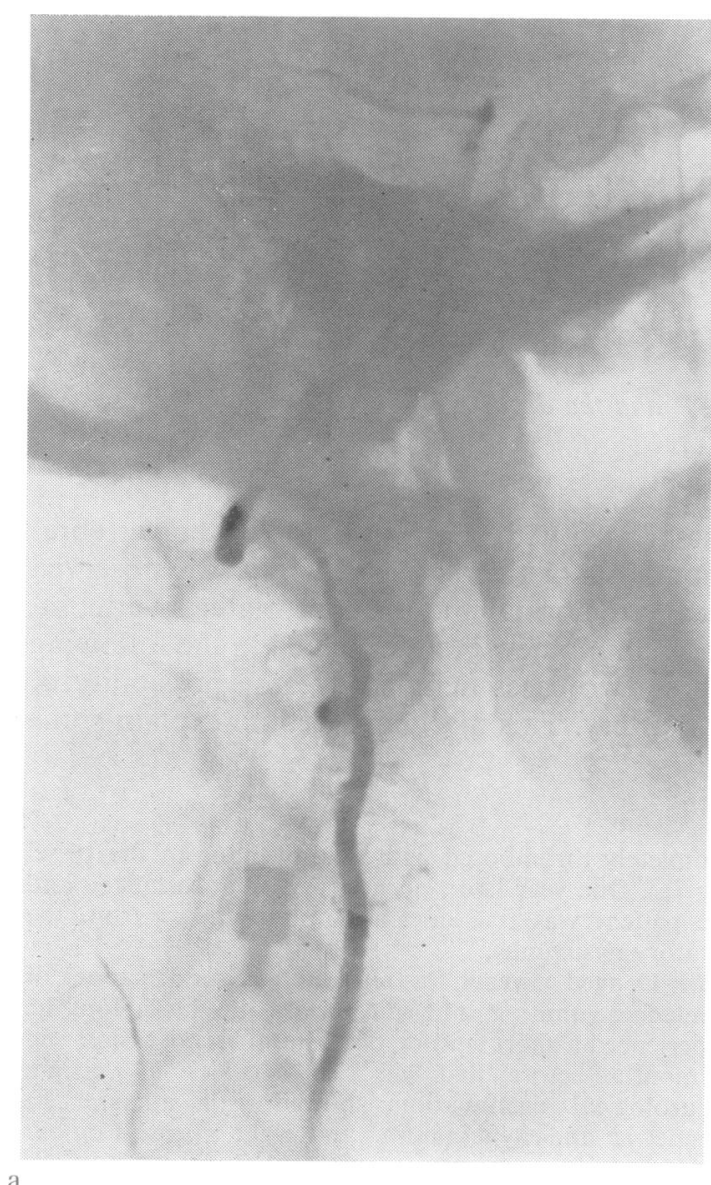

were observed in 16 cases $(36 \%)$. In eight cases arteriography showed insignificant lesions or was normal.

\section{Discussion}

Many reports deal with vertebro-basilar strokes, most of which are related to occlusion of the vertebral artery and especially of its intracranial portion. ${ }^{1-11}$ Fischer, ${ }^{12}$ from anatomical studies, found $14 \%$ of stenosis of the vertebral artery in 162 cases, but none was symptomatic. He concluded that lesions of the vertebral artery in its cervical portion, rarely led to stroke. ${ }^{13}$ Indications for surgery for cervical stenosis are mainly based on vertebro-basilar insufficiency with transient ischaemic manifestations. ${ }^{14}$ The two cases reported here, concern stroke with permanent signs associated with severe stenosis of the cervical vertebral artery.

Stenosis of the vertebral artery, as in the carotid artery, may cause symptoms by two mechanisms.

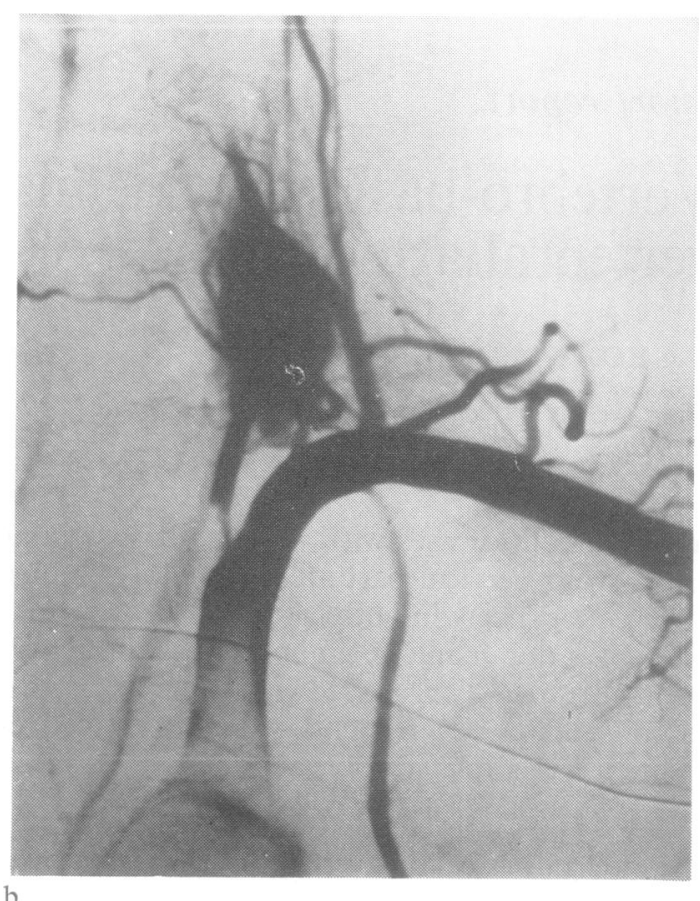

Figure (a) Left vertebral arteriography:marked stenosis between $C 2$ and $C 1$ of the left vertebral artery. (b) Left vertebral arteriography:severe stenosis at the ostium of the left vertebral artery. Slow filling of the artery above the stenosis.

The most frequent is a reduction of flow in the vertebro-basilar system. This mechanism is suspected in bilateral lesions or when associated with carotid and vertebral lesions. In our series, 20 occlusions were discovered after a stroke in 17 patients. ${ }^{11}$ In 16 cases bilateral lesions were found presumably causing a fall of blood flow. But in 16 other cases, the lesion was unilateral, and the controlateral vertebral artery was of good size, as in the two cases reported here. In these cases, we suspect an embolic mechanism, particularly in a case with cerebellar or occipital infarct with a normal posteriorinferior cerebellar artery and posterior cerebral artery.

Embolism is frequently advanced to explain infarcts in the carotid artery territory, but usually it may only be presumed in the vertebro-basilar system. ${ }^{4}$ Nevertheless, embolism in the posterior circulation has been documented on post-mortem examination. ${ }^{1-7}$ Meyer $^{15}$ and Sundt ${ }^{16}$ also have 
emphasised the rôle of embolism from proximal vertebro-basilar occlusion. Strokes from non-atheromatous lesions also have been reported. ${ }^{15-18}$ Fischer ${ }^{12}$ states that only $4 \%$ of vertebral atheromatous stenosis show ulceration. Severe stenosis, at least, seems to produce a high risk of embolism such as on the carotid artery. As occlusions of the vertebral artery are often diagnosed late after the onset of ischaemia (average 1 month in our cases), ischaemia could sometimes be related to embolism from stenosis changing to thrombosis when arteriography is done. These points should be taken into account when new techniques of revascularisation (occipital artery to posterior-inferior cerebellar artery ${ }^{9-16}$ and carotid artery to vertebral artery 1920 ) are discussed. The best indications should be bilateral lesions and unilateral symptomatic stenosis.

\section{References}

${ }^{1}$ Fischer CM, Karnes WE, Kubik CS. Lateral medullary infarction. The pattern of vascular occlusion. $J$ Neuropath Exp Neurol 1961 ;20:323-79.

${ }^{2}$ Sypert GW, Alvord EC. Cerebellar infarction. A clinicopathological study. Arch Neurol 1975;32: 357-63.

${ }^{3}$ Peiffer J, Haas H, Boellard J. Basilaris-vertebralisaneurysmen als ursche schneibarer halswirbelsaeulensyndrome.Klinische und morphologische untersunchungen an duenf klinisch diagnostizierten faellen. Dtsche Med Wschr 1977;103 8:331-5.

${ }^{4}$ Caplan LR. Occlusion of the vertebral or basilar artery. Follow-up analysis of some patients with benign outcome. Stroke 1979;10 3:177-82.

${ }^{5}$ Yates PO, Hutchinson EC. Carotido-vertebral stenosis. Lancet $1957 ; 1: 2-8$.

${ }^{6}$ Yates PO, Hutchinson EC. Cerebral infarction. The role of stenosis of the extracranial cerebral arteries. Spec Rep Sec Med 1961;300:1-95.

${ }^{7}$ Castaigne P, Lhermitte F, Gautier JC, et al. Arterial occlusions in the vertebrobasilar system. A study of forty four patients with post-mortem data. Brain 1973;96:133-54.

${ }^{8}$ Escourolle R, Hauw JJ, Der Agopian P, Trelles L.
Les infarctus bulbaires. Etudes des lésions vasculaires dans 26 observations. J Neurol Sci 1976;28: 103-13.

${ }^{9}$ Khodadad G, Singh RS, Olinger CP. Possible prevention of brain stem stroke by microvascular anastomosis in the vertebral system. Stroke 1977;8:316-21.

${ }^{10}$ Thompson JR, Simmons CR, Hasso AN, Hinshaw DB. Occlusion of the intradural vertebro-basilar artery. Neuroradiology 1978;14:219-29.

${ }^{11}$ George B, Laurian C. Occlusion de l'artère vertébrale. A propos de 33 cas. Implications thérapeutiques. Neurochirurgie 1981 (in press).

${ }^{12}$ Fischer CM, Gore I, Okabe N, White PD. Atherosclerosis of the carotid and vertebral arteries. Extracranial and intracranial. J Neuropath Exp Neurol $1965 ; 24: 455-76$.

${ }^{13}$ Fischer CM. Occlusion of the vertebral arteries causing transient basilar symptoms. Arch Neurol 1970;22:12-19.

${ }^{14}$ Cormier JM, Laurian C. Surgical management of vertebro-basilar insufficiency. $J$ Cardiovasc Surg 1976;17:205-23.

${ }^{15}$ Meyer JS, Sheehan S, Bauer R. An arteriographic study of cerebro-vascular disease in man. I. Stenosis and occlusion of the vertebro-basilar arterial system. Arch Neurol 1960;2 :27-45.

${ }_{16}$ Sundt T, Whisnant J, Piepgras D, Campbell J, Holman C. Intracranial by-pass grafts for vertebro-basilar ischemia. Mayo Clin Proc 1978;53:12-18.

${ }_{17}$ Mauguiere F, Bouillat J, Ferry AM, Goutelle A, Garde A. Syndrome de Walleberg dû à un anévrysme fusiforme de l'artère vertébrale droite extracranienne d'origine traumatique probable. Rev Otoneuro-ophthalmol 1978;50:1:63-7.

${ }^{18}$ George B, Laurian C, Derome P, Guilmet D. Pontage sous-clavier vertebral en $\mathrm{C} 1-\mathrm{C} 2$ pour dysplasie anévrysmale. Intérêt et possibilité de l'abord chirurgical de la vertébrale en C1-C2. Neurochirurgie 1979;25:124-8.

${ }^{19}$ Corkill G, French BN, Michas C, Cobb CA, Mims TJ. External carotid vertebral anastomosis for vertebrobasilar insufficiency. Surg Neurol 1977;7:109-15.

${ }^{20}$ George B, Laurian C. Surgical approach to the whole length of the vertebral artery with special reference to the third portion. Acta Neurochirurgica 1980;51 : 259-72. 